\title{
NECESSÁRIA EVOLUÇÃO DAS AUDIÊNCIAS CÍVEIS EM TEMPOS DE PANDEMIA (COVID-19)
}

Flavia Caroline Marsola, Fernando da Costa Machado Filho, Leandro Vieira dos Santos, Sarah Carolina Colorado Borges

Universidade do Oeste Paulista - UNOESTE, Presidente Prudente, SP. E-mail: fla marsola@hotmail.com

\section{RESUMO}

O presente artigo tem como objetivo discorrer sobre as audiências virtuais durante o período de distanciamento social em razão do estado pandêmico causado pela COVID-19. Até então, a audiência virtual era procedimento utilizado de forma esporádica. Entretanto, a atual situação de distanciamento trouxe a necessidade da utilização das audiências virtuais como procedimento rotineiro, visto a impossibilidade da presença física dos componentes do processo nos Tribunais. Logo, tornando-se comum a prática, necessária foi a regulamentação dos procedimentos, de modo a assegurar os princípios base do processo. Dessa forma, foi de grande importância a adaptação às audiências por videoconferência, surgindo então uma evolução quanto aos atos processuais digitais. Várias questões foram levantadas quanto a prática das audiências on line. O Judiciário enfrentou satisfatoriamente as mudanças impostas pelo distanciamento social, restando então a possível adoção da audiência virtual para após pandemia. $O$ devido processo legal foi garantido, sendo várias questões superadas com saídas práticas adotadas pelos julgadores. A metodologia aplicada é a qualitativa com a coleta de dados por pesquisa bibliográfica e jurisprudencial, bem como notícias de jornais, informativos e revistas eletrônicas. A legislação também foi adotada como fonte de estudo.

Palavras-chaves: Audiências Virtuais. Audiências Cíveis em Pandemia. Devido Processo Legal em Pandemia.

\section{NECESSARY EVOLUTION OF CIVIL HEARINGS IN PANDEMIC TIMES (COVID-19)}

\begin{abstract}
This article aims to discuss virtual audiences during the period of social distance due to the pandemic state reported by COVID-19. Until then, the virtual audience was a sporadic procedure. However, the current situation of distance has brought the need for the use of virtual hearings as a routine procedure given the impossibility of the physical presence of the components of the process in the Courts. Therefore, as the practice became common, it was necessary to proceed with the procedures, in order to ensure the basic principles of the process. Thus, it was of great importance to adapt to audiences by videoconference, thus emerging an evolution regarding digital procedural acts. Several questions were raised regarding the practice of online hearings. The judiciary satisfactorily faced the changes imposed by the social distance, leaving then the approval of the virtual audience for after the pandemic. Due legal process was guaranteed, with several super issues regarding the practices adopted by the judges. The applied methodology is qualitative with the collection of data by bibliographic and jurisprudential research, as well as news from newspapers, newsletters and electronic magazines. The legislation was also adopted as a source of study. Keywords: Virtual Audiences. Pandemic Civil Audiences. Due Pandemic Lawsuit.
\end{abstract}




\section{INTRODUÇÃO}

O ano de 2020 será considerado como um marco de mudanças para a sociedade. A pandemia causada pelo vírus (SARS-COV 2) infectou milhares de pessoas no mundo e no Brasil.

A medida mais eficaz para evitar o contágio da doença foi o distanciamento e o isolamento sociais. As pessoas que puderam, passaram a desenvolver seu trabalho em casa. Magistrados, serventuários, colaboradores e advogados iniciaram o trabalho remoto. As audiências foram canceladas sem previsão de redesignação.

Com o passar dos dias, um novo normal foi sendo incorporado pela população. A sociedade começou a se adaptar. As reuniões pelas plataformas na rede mundial de computadores tornaram-se parte do cotidiano de muitas pessoas. Neste contexto, surge no âmbito do Poder Judiciário a necessária implantação de novas tecnologias. À vista disso, algumas audiências virtuais foram realizadas, e os resultados foram positivos, passando a fazer parte do cotidiano de muitas varas e seções judiciárias.

Surgiram então discussões principiológicas, que trataremos neste estudo, assim como discussões sobre o futuro das audiências virtuais.

Este artigo pretende abordar a necessária evolução das audiências cíveis em tempos de pandemia: a adoção do meio virtual e o que poderá restar dessa evolução após o distanciamento social.

\section{MÉTODOS}

A abordagem foi realizada de modo qualitativo, conforme doutrina específica (MEZZAROBA, 2017).

Para tanto, foi empregada a coleta de dados por pesquisa bibliográfica e jurisprudencial, bem como notícias de jornais, informativos e revistas eletrônicas. A legislação também foi adotada como fonte de estudo.

$\mathrm{O}$ estudo passou pelos seguintes tópicos: os atos processuais virtuais no direito brasileiro; as audiências e os princípios correlatos; as audiências virtuais; a necessária evolução das audiências virtuais em época de pandemia, e o que restará das audiências virtuais após a pandemia.
Logo, o fundamento da presente pesquisa é a evolução das audiências virtuais cíveis, que passaram por rápido desenvolvimento face à pandemia, bem como a expectativa de que este meio continue a ser utilizado após distanciamento e isolamento sociais.

\section{RESULTADOS}

Os resultados obtidos com a utilização das audiências virtuais cíveis foram positivos, frente à problemática proposta. Conseguimos alcançar celeridade processual com a otimização do tempo, economia processual com a continuidade da prática de atos judiciais, a possibilidade de encerramento de muitos processos pela utilização de audiências de conciliação e até mesmo de instrução. Embora continuem existindo problemas como o acesso à internet e dificuldade de alguns na utilização dessas tecnologias, o saldo foi positivo, tornando a audiência virtual uma ótima ferramenta a ser utilizada também no futuro, possibilitando até mesmo a própria inclusão do jurisdicionado e advogados pelo vencimento de distâncias físicas. O despertar tecnológico foi rápido e bem aceito, causando admiração no meio jurídico. Não houve prejuízo ao contraditório e ampla defesa, vislumbrando assim a possibilidade de que tais audiências sejam incorporadas ao cotidiano cível brasileiro.

\section{DISCUSSÃO}

\subsection{Atos processuais virtuais no direito brasileiro}

A crise ocasionada pela Covid-19 trouxe ao mundo problemas sociais, sanitários e econômicos, refletidos no Judiciário brasileiro.

O isolamento social foi necessário, haja vista a inexistência de vacina contra a doença e a necessidade de muitos trabalhadores desenvolverem habilidades home office. Foi o que ocorreu com o Judiciário brasileiro.

Atos processuais eletrônicos já eram conhecidos em nosso ordenamento jurídico, contando com legislação específica, como a Lei Federal 11.419/06 de 19.12.2006, embora ainda não tivéssemos a realização de audiências virtuais em matéria cível.

Muitos países, a título de exemplo, os EUA (Estados Unidos da América), adotaram as audiências virtuais, a vídeo conferencia e o vídeolink em 1983, com o fim de minimizar o contato das vítimas com seus agressores. 
Por sua vez, a Itália adotou esse sistema como forma de reprimir a máfia, embora atualmente utilizado para oitiva de testemunhas. Não obstante, a União Europeia ratificou em 2000 o Tratado de Assistência Judicial em matéria penal, o qual implementou a possibilidade de realização de atos processuais com a utilização de tecnologia audiovisual (BARROS, et al, 2006, p. 121).

O Código Penal Francês, desde 2001, prevê a utilização de meios eletrônicos para a comunicação de interrogatório dos acusados e a oitiva de testemunhas. Semelhantemente, com a adoção da Lei Geral sobre Cooperação Internacional, em matéria criminal, se admitiu no Reino Unido em 2003 a possibilidade de as testemunhas da Inglaterra, Escócia, Irlanda do Norte e do País de Gales prestarem depoimentos por videoconferência (BARROS et al, 2006, p. 121).

Nota-se que muitas são as legislações internacionais admitindo a utilização das denominadas Tecnologias da Informação e da Comunicação (TICS). O Brasil ratificou muitas dessas convenções, pactos e tratados. Nesse seguimento podemos citar o Pacto de San José da Costa Rica (art. 70, itens 5 e 6), o Estatuto de Roma do Tribunal Penal Internacional, a Convenção de Palermo e a Convenção de Mérida das Nações Unidas contra a Corrupção, que instituem as colaborações e produções de provas processuais por meios eletrônicos para proteger as vítimas e testemunhas.

No Brasil, a primeira experiência nesse sentido teria sido realizada em 27/08/1996, na cidade de Campinas/SP (LENZA, 2013, p. 1094).

Antes mesmo de regulamentação Federal, o Estado de São Paulo, sob o pretexto de competência legislativa concorrente (art. 24, XI, CF), promulgou a lei n. 11.819/2005, introduzindo a audiência por videoconferência (art. $1^{\circ}$ ).

Em 2009 o Congresso Nacional aprovou a Lei no 11.900, alterando dispositivos do CPP, prevendo a possibilidade de realização de interrogatório e outros atos processuais por sistema de videoconferência.

O CNJ editou a Resolução n. 105 de 2010, regulamentando os depoimentos, interrogatórios e oitiva de testemunhas por meio de sistema audiovisual, compelindo-se a desenvolver e disponibilizar a todos os tribunais sistemas eletrônicos de gravação por videoconferência.
A Resolução n. 542/2011 disciplinou o julgamento virtual em segundo grau de jurisdição no Tribunal de Justiça de São Paulo.

A seu turno, o Código de Processo Civil de 2015 adotou a realização de audiências virtuais consagrando-as em vários artigos, com o propósito de colher depoimento pessoal de parte bem como oitiva de testemunhas, nos casos em que ela resida em foro diverso daquele de tramitação do processo (arts. 385, § 3으, e 453, § $10)$. Acentue-se que essas predições estão em harmonia com a admissão geral da prática dos atos processuais por intermédio da videoconferência ou outro recurso tecnológico de transmissão de sons e imagens em tempo real (art. 236, § $3^{\circ}, \mathrm{CPC}$ ).

Portanto, parece-nos nítido que inúmeros foram os problemas enfrentados pelo Poder Judiciário brasileiro no decorrer dos tempos. Todavia, assim como existem pedras em meio aos caminhos, há também caminhos em meio às pedras. Por conseguinte, conclui-se que na mesma proporção com que a sociedade evolui e novos fatos surgem, inúmeras são as soluções codificadas para melhor atender à sociedade; trata-se da evolução dos atos processuais.

\subsection{Audiências virtuais e princípios correlatos.}

Os princípios, apesar de maior abstração, são tidos como normas jurídicas pela carga valorativa que carregam; tratam-se de mandados de otimização. Em tempos da Covid-19 são utilizados como fontes para resolução de problemas sociais e processuais surgidos ou agravados pela nova realidade. Acerca das audiências on line, percebemos alguns princípios peculiares. De acordo com Ada Pellegrini Grinover (2015, p. 74):

A ciência processual
estabeleceu preceitos
importantes que
caracterizam e moldam o
sistema processual, além
da existência de princípios
que não ficam presos a
técnicas, mas traz
acepções éticas, sociais e
políticas que transcendem
e amparam cada sistema,
seja comum a todos ou
específicos a cada um.

A Constituição Federa estabelece o princípio do contraditório (art. 5o, LV), segundo o qual aos litigantes, em processo judicial ou 
administrativo, e aos acusados em geral são assegurados o contraditório e ampla defesa, com os meios e recursos a ela inerentes. Nelson Nery Junior (2002, p. 128), preleciona que:

O princípio do
contraditório, além de
fundamentalmente
constituir-se em
manifestação do princípio
do estado de direito, tem
íntima ligação com o da
igualdade das partes e do
direito de ação, pois o
texto constitucional, ao
garantir aos litigantes o
contraditório e a ampla
defesa, quer significar que
tanto o direito de ação
quanto o direito de defesa
são manifestações do
princípio do contraditório.

Além dos já mencionados, o princípio da imediatidade, que se funde na colheita da prova oral diretamente realizada pelo juiz, sem intermediários, para possibilitar que ele tenha contato e assim haja motivação da sua decisão, encontra-se em vias de adequação ao ambiente virtual. Sobre este princípio, ensina Renato Saraiva (2016, p.46) que: "Permite um contato direto do juiz com as partes, testemunhas, peritos, terceiros e com a própria coisa litigiosa, objetivando firmar o seu convencimento, mediante a busca da verdade real".

A seu turno, o isolamento social e a pandemia da COVID 19 trouxeram consigo preocupação quanto à efetividade dos princípios gerais do Processo Civil na Constituição Federal em sede de audiências virtuais. Surgem então discussões quanto ao cumprimento desse patamar mínimo principiológico. Neste sentido é a reportagem da Folha de São Paulo:

$$
\begin{aligned}
& \text { Para entidade da classe } \\
& \text { dos advogados ouvidas } \\
& \text { pela Folha, entre os } \\
& \text { problemas da medida } \\
& \text { estaria o risco de } \\
& \text { testemunhas rerem } \\
& \text { manipuladas ou coagidas } \\
& \text { em seus depoimentos. } \\
& \text { Elas questionam também } \\
& \text { a viabilidade de se garantir } \\
& \text { que uma testemunha não } \\
& \text { ouça às demais. } \\
& \text { Na Justiça estadual, } \\
& \text { porém, o uso da } \\
& \text { ferramenta tecnológica }
\end{aligned}
$$

está avançando. A direção do TJ-SP relatou que ainda não fez um levantamento sobre o número de juízes que está utilizando o recurso, mas avalia a experiência como bastante positiva. (FERREIRA, Flávio; GALF, Renata, 2020).

Também podemos mencionar fatores como a instabilidade da internet e a falta de recursos de jurisdicionados, que acabam por colocar em risco o direito fundamental do acesso à justiça e, consequentemente, o devido processo legal. Em notícia do Site do Conselho Federal da OAB encontramos que:

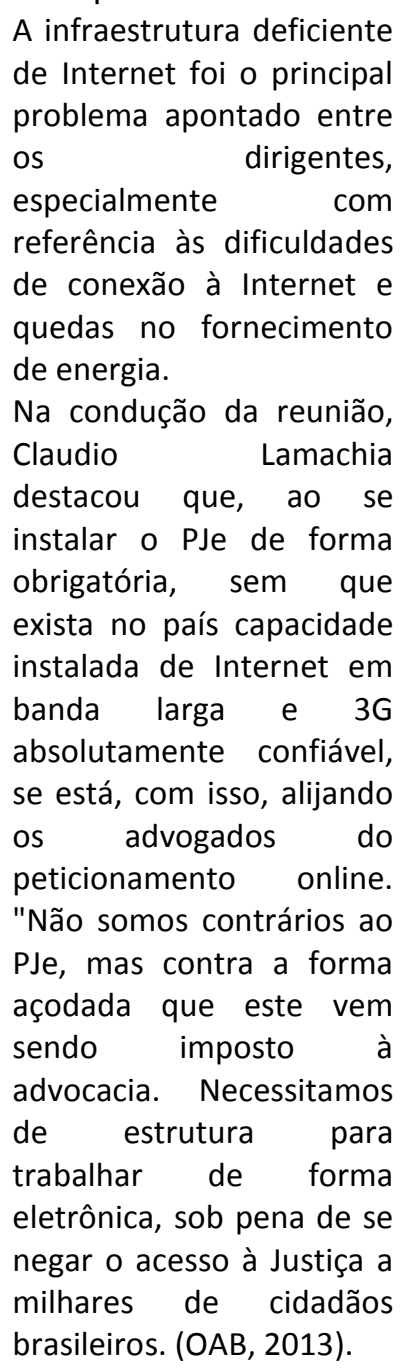

Contudo, é possível que o devido processo legal seja obedecido sem contato físico e social, de forma que se respeitem as medidas com base nas normas fundamentais do processo civil, artigos 10 ao 12 do CPC.

Ainda, quanto à discussão acerca daqueles que não possuem recursos tecnológicos 
e estão sujeitos a eventual mitigação do direito fundamental ao acesso à justiça, cumpre esclarecer que o princípio da adaptabilidade permite ao juízo a possibilidade de flexibilizar o procedimento de forma a atingir a sua finalidade. Tanto é verdade que o Enunciado n. 35 da Escola Nacional de Formação e Aperfeiçoamento de Magistrados (ENFAM, [2019]) diz que:

Além das situações em que a flexibilização do procedimento autorizada pelo art. 139, $\mathrm{VI}$, do $\mathrm{CPC} / 2015$, pode o juiz, de ofício, preservada a previsibilidade do rito, adaptá-lo às especificidades da causa, observadas as garantias fundamentais do processo.

Jorge Bezerra em seu artigo "A Pandemia e a Marcha Processual" traz que:

Antes de qualquer medida a ser tomada pelo Judiciário, as partes dos processos, orientadas por seus advogados, devem se imbuir do ânimo de cooperar com as medidas de enfrentamento ao COVID-19, a bem da não paralisação completa do Sistema de Justiça, de maneira a não oporem resistências infundadas, vazias de justificativas, em relação às medidas total virtualização da persecução do processo eletrônico, até o fim deste estado de coisas ora vivido (art. 60 do CPC). (MARTINS, 2020).).

Outro ponto plausível a se destacar é a celeridade processual, e sobre ela afirma o estudioso Edilson Mougenot Bonfim (2009, p. 343-345):

são assegurados a
razoável duração do
processo e os meios que
garantam a celeridade de
sua tramitação." o
interrogatório feito por
intermédio da
videoconferência busca
tornar efetiva e célere a
prestação jurisdicional.
Não há que se falar em
afronta aos princípios da
ampla defesa e
publicidade, uma vez que
o acusado, no
interrogatório tem contato
direto e irrestrito com o
magistrado e com seu
advogado, sendo a
publicidade garantida
mediante a tecnologia. A
obrigatoriedade da de da
presença do defensor,
bem como sua prévia e
reservada entrevista com
o réu, elide o argumento
das possíveis pressões
externas que possam
macular a autodefesa e o
calor probatório do ato.
Ademais, o réu pode
sofrer pressões mesmo na
presença do juiz, em
virtude de anterior
ameaça.

Na notícia "Realização de audiências por videoconferência garante celeridade a processos", o conselheiro Walter Nunes do Conselho Nacional de Justiça:

O uso da tecnologia, segundo o conselheiro, dá maior agilidade à tramitação dos processos sempre que as partes ou testemunhas estão em local diverso do juiz. Além da celeridade e da economia com passagens, hospedagens e translado, a técnica também assegura o princípio do juiz natural e da identidade física, já que é - próprio magistrado responsável pelo julgamento que realiza a escuta e colhe a prova. (BRAGA, 2010). 
Além da duração razoável do processo, também existe a preocupação com a economia processual que se demonstra eficiente diante da ampliação dos meios tecnológicos.

Não havendo possibilidade de que a audiência seja realizada de modo on line, bem como descartado o julgamento antecipado do mérito, a suspensão dos autos é medida que se impõe, sob a fundamentação de força maior, como previsto no artigo $313, \mathrm{VI}$ do $\mathrm{CPC}$, in verbis:

Art. $\quad 313$.

Suspende-se

0 processo:

(...)

$\mathrm{VI}$ - Por motivo

de força maior;

O CPC/2015 criou dispositivos sobre a videoconferência, como os artigos 236, §3o; 385, $\S 3$; 453, §§1으 e §2ㅇ; 461, §2ㅇ; e 937ㅇ, §4ㅇ. Com isso, se vê que a videoconferência tem sido usada cada vez mais como forma de evitar o deslocamento, diminuir custos e ampliar o acesso à justiça.

Manuel Castells (2015, p. 172 e 224) destaca que "A era da internet foi aclamada como o fim da geografia e como a comunicação é a essência da atividade humana, todos os domínios da vida social estão sendo modificados pelos usos disseminados da Internet".

Conforme observamos, existem aspectos positivos na adoção de audiências on line. É ferramenta que evita deslocamento, diminui custos, e amplia o acesso à justiça em tempos de pandemia.

Contudo, como em outros sistemas e institutos jurídicos, a audiência virtual não é perfeita, assim como a presencial também não. Dessa forma, devemos levar em consideração os aspectos positivos e sua preponderância sobre os negativos.

\subsection{Audiências virtuais}

A realização de atos processuais de forma virtual, ou remota, não é novidade. Conhecida como a lei da videoconferência, a Lei 11.900 de 2009 trouxe mudanças marcantes para o Código de Processo Penal brasileiro, inserindo a possibilidade de interrogatório por videoconferência. In verbis, avulta o art. 185 , §2:

$\S 2^{\circ}$ Excepcionalmente, 0 juiz, por decisão fundamentada, de ofício ou a requerimento das partes, poderá realizar o interrogatório do réu preso por sistema de videoconferência ou outros recursos tecnológicos de transmissão de sons e imagens em tempo real, desde que a medida seja necessária para atender uma das seguintes finalidades (BRASIL, 1941).

Dessa forma, preceitua o Código de Processo Penal pela possibilidade de interrogatório por videoconferência, desde que de forma excepcional e justificada. O próprio legislador taxa sua aplicação nos incisos seguintes ao parágrafo supramencionado, isto é, para prevenir risco à segurança pública, para viabilizar a participação do réu no referido ato processual, para impedir a influência do réu no ânimo da testemunha ou vítima e para responder à gravíssima questão de ordem pública. Segundo Eugênio Pacelli:

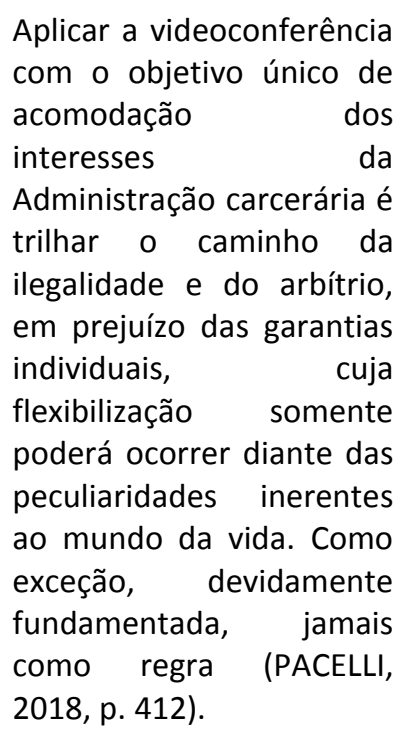

Tendo-se estabelecido o trabalho remoto, ante a impossibilidade de encontros físicos, medidas alternativas foram tomadas para dar continuidade à prestação jurisdicional. Desse modo, portarias foram editadas para a regulamentação das audiências virtuais, como por exemplo a Portaria $n^{\circ} 61 / 2020$, do Conselho Nacional de Justiça, que instituiu a Plataforma Emergencial de Videoconferência para a realização de audiências e sessões de julgamento nos órgãos do Poder Judiciário. 
O Tribunal de Justiça do Estado de São Paulo em Comunicado CG n 284/2020 regulou as sessões virtuais:

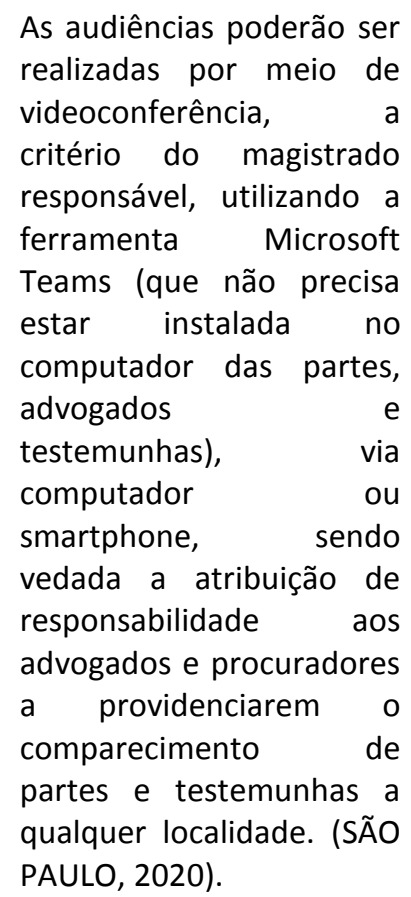

As audiências virtuais têm acontecido sob essa nova perspectiva.

As intimações devem conter todas as informações necessárias para que a parte participe da sessão, como por exemplo o link de acesso à plataforma e a disponibilização de um advogado remoto, em audiências de mediação e conciliação (Juizado Especial Cível e CEJUSC), caso uma das partes ainda não seja representada por um.

Ainda, vários óbices puderam ser apontados quanto ao funcionamento desses procedimentos, tendo em vista a incomunicabilidade das testemunhas (artigo 456 do $(P C)$, por exemplo. É mais um de vários problemas a serem resolvidos que, no mais, poderiam configurar causa de nulidade relativa, isto é, passíveis de suprimento e até mesmo convalidação. Dessa forma, só há nulidade no processo civil com a comprovação de prejuízo, de modo que os atos com vício de forma podem ser convalidados se atingirem sua finalidade.

Segundo o parágrafo único do art. 283 do CPC: Dar-se-á o aproveitamento dos atos praticados desde que não resulte prejuízo à defesa de qualquer parte (BRASIL, 2015).

Cabe frisar, também, o posicionamento do Conselho Nacional de Justiça, no sentido de chancelar a prática das audiências virtuais, não apenas considerando o princípio da duração razoável do processo, mas também forma de reduzir gastos.

Isso é visível, por exemplo, na notícia publicada no site do CNJ, em 21 de janeiro de 2020, intitulada "Videoconferência muda o formato de audiências", anotando que:

A videoconferência é uma
tecnologia que permite a
transmissão de imagem e
som entre os
interlocutores.
audiência, o ambiente
virtual proporciona a
interação em tempo real
para os que estão
geograficamente
distantes, sendo assim
uma solução segura para
redução de custos, riscos e
tempo (CNJ, 2020).

Entretanto, a permanência desses procedimentos na rotina comum, fora do período pandêmico, nos leva a considerar aspectos básicos do processo civil, para a aplicação cotidiana. Como realizar? Ex officio, a requerimento, manifestação oral das partes, substituição das alegações orais por memorais, v.g.

Apesar dos problemas, não restam dúvidas que, adotando-se as audiências por videoconferência cotidianamente, resultaria em celeridade e economia processuais, além da otimização do tempo para a prestação de tutela jurisdicional e a real evolução para um processo ainda mais virtual. Neste contexto, o próximo tópico.

\subsection{Necessária evolução das audiências virtuais em época de pandemia}

Inúmeras foram as consequências causadas pela COVID-19 no âmbito do Poder Judiciário. Atendimentos presenciais limitados, prazos e processos físicos suspensos, audiências presenciais canceladas, entre outros.

É sabido que as adaptações foram muitas e necessárias. Nesse aspecto surge a evolução da virtualização dos atos processuais e o consequente progresso, difundido ao mesmo tempo como solução aos entraves decorrentes do isolamento social.

O escritor israelense Yuval Noah Harari afirma em "o mundo depois do coronavírus" que: As decisões que em tempos normais podem 
levar anos de deliberação são aprovadas em questão de horas. Tecnologias imaturas e até perigosas são colocadas em serviço, porque os riscos de não fazer nada são maiores. (HARARI, 2020, tradução nossa).

A tecnologia é instrumento de ampliação das fronteiras terrestres e, contemporaneamente, processuais. Trata-se de recurso utilizado para a manutenção do trabalho em épocas de isolamento e distanciamento sociais, dando azo inclusive à prática de atos processuais, como audiências e sessões de julgamento virtuais.

Não obstante, o Código de Processo Civil (art. 236, $\S 3^{\circ}$ ), como instrumento de manutenção ritual, prevê a possibilidade da prática de atos virtuais. Destaque-se que, muito embora positivado, por anos a praxe jurídica dominante não vislumbrava a sua efetiva utilização. Contudo, o cenário atual cobra um verdadeiro requinte de evoluções.

As audiências presenciais garantem interação entre o juiz e as partes, o que por vezes tem lá os seus benefícios, principalmente em litígios com alto grau de complexidade.

Nessa perspectiva o princípio da cooperação esboçado no Código de Processo Civil (art. 6ㅇ) introduz a ideia de solidariedade e coadjuvação entre as partes, já que a norma jurídica individualizada interessa a todos. Assim, é possível que manifestem em boa-fé a vontade pela audiência virtual, ainda que por intermédio de negócio jurídico processual (art. 190, do Código de Processo Civil).

No momento atual inúmeras são as fragilidades e vulnerabilidades tecnológicas das Comarcas e Sessões da OAB. Logo, diversos fatores devem ser analisados, levando-se em consideração condições materiais e estruturais dos envolvidos.

Neste sentido, determina a Resolução 314 do CNJ $\left(\right.$ art. $6^{\circ}, \S 3^{\circ}$ ):

As audiências em primeiro grau de jurisdição por meio de videoconferência devem considerar as dificuldades de intimação de partes e testemunhas, realizando-se esses atos somente quando for possível a participação, vedada a atribuição de responsabilidade aos advogados e procuradores em providenciarem o comparecimento de partes e testemunhas a qualquer localidade fora de prédios oficiais do Poder Judiciário para participação em atos virtuais (CNJ, 2020).

No mais, por questão de ordem, acentue-se que o CNJ acatou pedido de liminar da $\mathrm{OAB} / \mathrm{SP}$ contra audiências de instrução telepresenciais no TRT-15, sem a concordâncias das partes, conforme decisão expressa:

[...] constatada a pertinência da pretensão ora deduzida em relação ao entendimento já firmado neste Conselho sobre a matéria nos autos do PP n. 3594- 51.2020, deixo de apreciar o feito em sede de liminar e avanço no mérito para julgar procedente 0 presente expediente para determinar que o TRT da 15a Região, nas hipóteses previstas no artigo 3ㅇ, parágrafo 3 어 da Resolução 314/2020 (apresentação de contestação, impugnação ao cumprimento de sentença, embargos à execução, defesas preliminares de natureza cível, trabalhista e criminal, inclusive quando praticados em audiência, e outros que exijam a coleta prévia de elementos de prova), suspenda o ato, quando houver pedido expresso de alguma parte sobre a impossibilidade da sua prática, independente de prévia decisão do juiz. Nos demais casos, a suspensão dependerá de decisão fundamentada do magistrado (OAB, 2020). 
Todavia, como assunto espinhoso, as discussões não param por aí. O Tribunal de Justiça de São Paulo, por intermédio do Conselho Superior da Magistratura, editou provimento CSM $n^{\circ} 2554 / 2020$, que exclui a necessidade do consentimento prévio das partes durante a pandemia, contrapondo a orientação do Conselho Nacional de Justiça.

$$
\begin{aligned}
& \text { §4ㅇ. Poderão ser } \\
& \text { realizadas audiências por } \\
& \text { videoconferência, } \\
& \text { observada, nesse caso, a } \\
& \text { possibilidade de intimação } \\
& \text { e de participação das } \\
& \text { partes e testemunhas no } \\
& \text { ato, por meio do link de } \\
& \text { acesso da gravação junto } \\
& \text { ao Microsoft OneDrive, a } \\
& \text { ser disponibilizado pelo } \\
& \text { juízo, observadas as } \\
& \text { demais disposições dos } \\
& \text { Comunicados CG no } \\
& 284 / 2020 \text { e no } 323 / 2020 \\
& \text { (SÃO PAULO, 2020). }
\end{aligned}
$$

Portanto, resta nítido que foi dado início à transposição dos obstáculos para a realização das audiências virtuais.

\section{O que restará das audiências virtuais após a pandemia}

O Poder Judiciário enfrentou de forma satisfatória as urgências impostas pela COVID-19. Inúmeras foram as implementações realizadas para melhor identificar os resultados e enveredar o futuro do trabalho remoto. O CNJ iniciou pesquisa através de questionário enviado por ofícios aos tribunais.

O Poder Judiciário enfrentou de forma satisfatória as urgências impostas pela COVID-19. Inúmeras foram as implementações realizadas para melhor identificar os resultados e enveredar o futuro do trabalho remoto. O CNJ iniciou pesquisa através de questionário enviado por ofícios aos tribunais.

O Juiz Fernando Hoffman, coordenador da Escola Judicial do TRT-9 e membro do Núcleo Permanente de Métodos Consensuais de Solução de Conflito (Nupemec) do Tribunal de Justiça do Paraná, pronunciou que "Cabe a nós fazermos de uma crise uma oportunidade para aperfeiçoarmos a prestação jurisdicional".

A reportagem da Folha de São Paulo, "Justiça faz acordos virtuais para ações não pararem na pandemia", traz uma posição dos juízes a uma tendência de continuidade às audiências virtuais:

Apesar de terem sido implementadas como solução para viabilizar o andamento da Justiça durante a quarentena, as audiências virtuais são vistas como um instrumento que deverá se manter em uso mesmo após o fim da pandemia. $\mathrm{Na}$ opinião dos magistrados, esse tipo de solução reduz custos e agiliza os processos.

A juíza Heloisa Loyola, do TRT-2, considera que a adoção dos procedimentos a distância é um "caminho sem volta". Ela considera, porém, que não serão todos os processos em que as audiências serão virtuais, já que algumas ações, de maior complexidade não poderão ser substituídas. Como vantagens das videoconferências, ela cita a agilidade e a economia de recursos públicos.

O magistrado Bruno Takahashi, coordenador da Central de Conciliação do TRF-3 em SP, segue linha semelhante: "O que a gente vem notando é que as audiências virtuais tendem a durar menos", afirma, citando que há menos chances de atrasos. Isso ocorre, entre outros motivos, pelo fato de as partes não terem de se deslocar para chegar até o fórum. (MUNHOZ, 2020).

O CNJ também se posicionou positivamente quanto à permanência das audiências virtuais. Em notícia publicada no site do CNJ, em 17 de julho de 2020, intitulada "Realidade na pandemia, sessões e audiências por videoconferência vieram pra ficar", enfatizouse o seguinte:

[...] A partir disso, o CNJ está montando cenários 
sobre como deve ser o uso da videoconferência nos atos processuais no póspandemia para apresentar uma diretriz consolidada para os tribunais sobre o uso dessa tecnologia de forma permanente.

"O uso da videoconferência veio para ficar e fará parte da nossa rotina. $O$ outro aspecto é como fazer isso, porque será necessário investimento e planejamento porque $\mathrm{o}$ uso das videoconferências tem que ser sustentável no tempo e nosso trabalho, agora, é preparar o terreno. Já que as videoconferências farão parte da nossa rotina, a questão é saber como fazer isso", destaca Gusmão.

Entre decisões que serão necessárias para a continuidade do uso desse instrumento estão escolhas sobre tecnologias a serem usadas e o nível de investimentos nessa modalidade. (OTONI, 2020).

Juízes apostam nas audiências virtuais, como um caminho sem volta para o nosso sistema judiciário. Geneir Marques, juiz da 8a Vara Criminal de Arapiraca, afirmou:

Toda crise abre caminhos e nos faz enxergar coisas que levariam certo tempo até serem enxergadas. A pandemia acelerou essa transformação na sociedade e no Judiciário. Entendo ser possível elas continuarem a ocorrer após a pandemia. As audiências virtuais trazem praticidade, evitam o deslocamento das partes e reduzem custos" (SETE SEGUNDOS, 2020).

Destaque-se a admirável velocidade pela qual o Judiciário reagiu aos efeitos da pandemia, bem como a consequente ruptura com as práticas tradicionais, e a introdução das tecnologias como forma de promover o acesso à justiça.

Neste sentido, o juiz Lucas Lopes Dória Ferreira, da 4ạ Vara de Palmeira dos Índios, traz uma desejável perspectiva para o pós-pandemia:
A ferramenta virtual é mais um caminho de acesso à Justiça. "Não há por que fechar essa porta de entrada pós-pandemia. O acesso físico pode conviver com o virtual, não são excludentes. Quem puder, acessa virtualmente; quem precisar, comparece fisicamente. Para isso, basta que o Judiciário adote, como ferramenta de trabalho, uma plataforma aberta na web, como já está fazendo através do Google Meet (SETE SEGUNDOS, 2020).

Dessa forma, existe uma defesa em favor da audiência permanecer como prática no póspandemia. O Presidente do Tribunal de Justiça de Alagoas (TJ-AL) tem como ideia a conciliação entre o sistema virtual e presencial:

\begin{tabular}{|c|}
\hline $\begin{array}{l}\text { Devemos manter } \\
\text { virtualidade } \\
\text { audiências e, em grand } \\
\text { medida, das sessões da } \\
\text { Tribunal, ao lado de un } \\
\text { atendimento presencia }\end{array}$ \\
\hline
\end{tabular}

Doravante, não seria nenhum exagero acreditar que num futuro próximo o CNJ esboçaria novas diretrizes para implementar o uso da tecnologia de forma permanente.

Os textos colhidos dão conta do desenvolvimento rápido das técnicas on line e a experiência se mostrou positiva, sendo possível pensar na adoção, como regra, de audiência de conciliação virtual.

\section{CONSIDERAÇÕES FINAIS}

Como apontado, o surgimento do coronavírus (SARS-COV-2) trouxe consigo 
profundas mudanças em vários aspectos da sociedade. O distanciamento social, como medida para conter o contágio da doença, fez com que o novo fosse instaurado, inclusive no Judiciário. Logo, para que não houvesse uma paralisação total da prestação da tutela jurisdicional, medidas tecnológicas foram aprimoradas a fim de suprir algumas necessidades nesse período caótico.

A audiência virtual cível foi uma dessas medidas, que já prevista no Código de Processo Civil, utilizada somente em ocasiões específicas e que agora teve grande importância para o andamento dos processos. Entretanto, vários foram os empecilhos encontrados quanto a sua prática, os quais pudemos entender serem supríveis tendo em vista a efetividade dos princípios essenciais do Processo Civil, como os do contraditório e da imediatidade.

Os resultados foram positivos, os processos com curso suspenso voltaram a seguir a marcha, sendo muitos deles extintos pela composição das partes em audiência virtual.

Dessa forma, além da celeridade processual e otimização do tempo, o procedimento da audiência por videoconferência causou um novo despertar tecnológico, que desde o surgimento dos processos digitais estava adormecido. As audiências cíveis virtuais fatalmente seriam implantadas com o passar do tempo, mas tiveram um "empurrãozinho" pelo isolamento social causado pela pandemia de Covid-19.

\section{REFERÊNCIAS}

BARROS, Marco Antonio de; et al. Internet e videoconferência no processo penal. Revista CEJ (Brasília), Brasília, Distrito Federal, n. X, p. 116125, 2006.

\section{BONFIM, Edilson Mougenot. Curso de Processo}

Penal. 4. ed. São Paulo: Editora Saraiva, 2009.

BRAGA, Mariana. Realização de audiências por videoconferência garante celeridade a processos. Agência CNJ de Notícias, 2010. Disponível em: https://www.cnj.jus.br/realizacao-de-audienciaspor-videoconferencia-garante-celeridade-aprocessos/. Acesso em: 15 jun. 2020.

BRASIL. Presidência da República. Lei no 13.105, de 16 de março de 2015. Institui o Código de Processo Civil. Brasília, 2015. Disponível em: http://www.planalto.gov.br/ccivil 03/ ato2015- 2018/2015/lei/l13105.htm. Acesso em: 02 ago. 2020.

BRASIL. Presidência da República. Decreto-lei no 3.689, de 3 de outubro de 1941. Institui o Código de Processo Penal. Brasília, 1941. Disponível em: http://www.planalto.gov.br/ccivil 03/decretolei/del3689.htm. Acesso em: 02 ago. 2020.

\section{CASTELLS, Manuel. A galáxia da internet:} reflexões/ sobre a internet, os negócios e a sociedade. Rio de Janeiro: Jorge Zahar Editor, 2015.

CNJ. Conselho Nacional de Justiça.

Videoconferência muda o formato de audiências. 2020.

Disponível em:

https://www.cnj.jus.br/videoconferencia-mudao-formato-de-audiencias/. Acesso em: $17 \mathrm{de}$ julho de 2020.

CNJ. Conselho Nacional de Justiça. Resolução $\mathbf{n}^{\circ}$ 314. 2020.

Disponível em: https://www.cnj.jus.br/wpcontent/uploads/2020/04/Resolu\%C3\%A7\%C3\%A 3o-n\%C2\%BA-314.pdf. Acesso em: 19 de março de 2021.

ENFAM. Escola Nacional de Formação e Aperfeiçoamento de Magistrados. 0 poder judiciário e o novo código de processo civil. [2019]. Disponível em: https://www.enfam.jus.br/wpcontent/uploads/2015/09/ENUNCIADOSVERS\%C3\%830-DEFINITIVA-.pdf. Acesso em: 15 fev. 2021.

FERREIRA, Flávio; GALF, Renata. Uso de videoconferência abre discussão sobre limites e vantagens da ferramenta na justiça. Folha de São Paulo, São Paulo, 2020. Disponível em: https://www1.folha.uol.com.br/poder/2020/05/ uso-de-videoconferencia-abre- discussao-sobrelimites-e-vantagens-da-ferramenta-najustica.shtml. Acesso em: 22 jul. 2020.

GRINOVER, Ada Pellegrini. Teoria Geral do Processo. 31. ed. São Paulo: Malheiros Editores LTDA, 2015.

HARARI, Yuval Noah. Yuval Noah Harari : the world after coronavirus, free to read. 2020. Disponível em: 
https://www.ft.com/content/19d90308-685811ea-a3c9-1fe6fedcca75. Acesso: 2 de ago. de 2020.

LENZA, Pedro. Direito Constitucional

Esquematizado. 17. ed. São Paulo: Saraiva. 2013.

MARTINS, Jorge Bezerra Ewerton. A Pandemia e a Marcha Processual. Jus Brasil, 2020. Disponível

em:

https://jorgebemartins.jusbrasil.com.br/artigos/8 31989801/a-pandemia-e-a-marcha-processual.

Acesso em: 15 jun. 2020.

MEZZAROBA, Orides; MONTEIRO, Cláudia Servilha. Manual de metodologia da pesquisa em Direito. 7. ed. São Paulo: Saraiva, 2017.

MUNHOZ, Fábio. Justiça faz acordos virtuais para ações não pararem na pandemia. Folha de São Paulo, 2020. Disponível em:

https://agora.folha.uol.com.br/grana/2020/07/ju stica-faz-acordos-virtuais-para-acoes-naopararem-na-pandemia.shtml. Acesso em: 22 jul. 2020.

NERY JUNIOR, Nelson. Princípios do Processo Civil na Constituição Federal, 7. ed. São Paulo: Revista dos Tribunais, 2002.

OAB. Ordem dos Advogados do Brasil. CNJ acata pedido de liminar da OAB SP contra audiências de instrução telepresenciais no TRT15, sem a consonância das partes. Jornal da Advocacia, São Paulo, 2020.

Disponível em: https://covid19.oabsp.org.br/poderesconstituidos/judiciario/cni-acata-pedido-deliminar-da-oab-sp-contra-audiencias-deinstrucoes-telepresenciais-no-trt15-sem-aconcordancia-das-partes/. Acesso em: 28 jul. 2020.

OAB. Ordem dos Advogados do Brasil. OAB aponta os cinco maiores problemas do PJE. 2013. Disponível em: https://www.oab.org.br/noticia/25217/oabaponta-os-cinco-maiores-problemas-doprocesso-judicial-eletronico. Acesso em: 22 jul. 2020.

OTONI, Luciana Realidade na pandemia, sessões e audiências por videoconferência vieram pra ficar. CNJ: Conselho Nacional de Justiça, 2020.
Disponível em: https:www.cnj.jus.br/realidadena-pandemia-sessoes-e-audiencias-porvideoconferencia-vieram-para-ficar/. Acesso em: 18 de julho de 2020.

PACELLI, Eugênio. Curso de processo penal. 22. ed. São Paulo: Atlas, 2018.

SÃO PAULO (Estado). Tribunal de Justiça.

Comunicado CG n 284/2020 (atualizado). 2020. Disponível em:

https://www.tjsp.jus.br/Corregedoria/Comunicad os/Comunicado?codigoComunicado=18763\&pagi na=1. Acesso em: 03 ago. 2020.

SARAIVA, Renato. MANFREDINI, Aryanna. Curso de Direito Processual do Trabalho. Salvador: Juspodium, 2016.

SETE SEGUNDOS. Juízes apostam em audiências virtuais após período de isolamento social. Sete segundos, Maceió, 2020. Disponível em: https://maceio.7segundos.com.br/noticias/2020/ 06/06/151118-juizes-apostam-em-audienciasvirtuais-apos-periodo-de-isolamento-social. Acesso em: 30 jul. 2020. 